\title{
"BENZO COM ESSA AQUI": CONHECIMENTO LOCAL DE PLANTAS UTILIZADAS NA BENZEÇÃO EM UMA COMUNIDADE DO MUNICÍPIO DE PORTO DE PEDRAS-AL
}

\author{
LEOMAR DA SILVA DE LIMA \\ NIVALDO AURELIANO LÉO NETO
}

\begin{abstract}
RESUMO
No município de Porto de Pedras, localizado no Litoral Norte do Estado de Alagoas, há o povoado de Lages onde a população, através da flora local, busca meios para o tratamento de seus problemas de saúde, havendo situações em que a melhora é alcançada a partir de consultas com benzedeiras e curandeiros. Tendo 0 entendimento que em cada contexto social as pessoas buscam métodos de cura a partir de suas necessidades terapêuticas, surgiram questionamentos a respeito dos males que necessitam dos cuidados dessas/es especialistas, bem como quais são as plantas utilizadas em seus processos de benzedura. Com a aplicação de dois diferentes questionários (questionário 1 direcionado às/aos especialistas e 0 questionário 2 destinado à população), foi possível identificar oito plantas utilizadas neste contexto, onde as concepções de doença e a garantia de cura legitimam essa prática dentro da população.
\end{abstract}

\section{PALAVRAS-CHAVE}

Conhecimento local; Plantas de Poder; Etnomedicina; Etnobotânica.

\section{"BENZO WITH THIS ONE": LOCAL KNOWLEDGE OF PLANTS USED FOR BLESSING (BENZIMENTO) INA COMMUNITY AT THE MUNICIPALITY OF PORTO DE PEDRAS-AL}

\begin{abstract}
In the village of Lages, situated at the municipality of Porto de Pedras located on the North Coast of the State of Alagoas, the population seeks ways to treat their health issues through the local flora. In this context, health improvement is often achieved by consultations with traditional healers (benzedeiras/curandeiros). Based on the assumpion that in each social context people seek healing methods based on their specific therapeutic needs, this text addresses issues such as wich illness require the care of these traditional specialists, and what are the plants used in the practices of benzimento ("blessing"). Applying two different questionnaires (questionnaire 1 directed to the specialists and questionnaire 2 intended for the population) it was possible to identify eight plants used in these healing practices. We also suggest that in this location the particular conceptions of disease and healing contribute to legitimize these practices within the population.
\end{abstract}

\section{KEYWORDS}

Local knowledge; Power plants; Ethnomedicine; Ethnobotany.

\section{"BENZO AVEC CELUI-CI": CONNAISSANCE LOCALE DES PLANTES UTILISÉES DANS LA BÉNÉDICTION DANS UNE COMMUNAUTÉ DE LA MUNICIPALITÉ DE PORTO DE PEDRAS-AL}

\section{RÉSUME}

Dans la municipalité de Porto de Pedras, située sur la côte nord de l'État d'Alagoas, se trouve le village de Lages où la population, par le biais de la flore locale, cherche des moyens de traiter leurs problèmes de santé et où des améliorations sont possibles. des consultations avec des guérisseurs (benzedeiras/curandeiros). Comprenant 
que dans chaque contexte social, les personnes recherchent des méthodes de guérison en fonction de leurs besoins thérapeutiques, des questions se posent quant aux maux qui nécessitent le soin de ces spécialistes, ainsi que les plantes utilisées dans leurs processus de bénédiction. En appliquant deux questionnaires différents (questionnaire 1 destiné aux spécialistes et questionnaire 2 destiné à la population), il a été possible d'identifier huit plantes utilisées dans ce contexte, où les conceptions de la maladie et la garantie de guérison légitiment cette pratique au sein de la population.

\section{MOTS-CLÉS}

Connaissances locales; Centrales électriques; Ethnomédecine; Ethnobotanique.

\section{"BENZO CON ESA AQUII": CONOCIMIENTO LOCAL DE PLANTAS UTILIZADAS EN LA BENDICIÓN EN UNA COMUNIDAD DEL MUNICIPIO DE PORTO DE PEDRAS-AL}

\section{RESUMEN}

En el municipio de Porto de Pedras, ubicado en la costa norte del estado de Alagoas, se encuentra el pueblo de Lages, donde la población, a través de la flora local, busca formas de tratar sus problemas de salud, y hay situaciones en las que se logra una mejora desde de consultas con sanadores (benzedeiras/curandeiros). Al comprender que en cada contexto social las personas buscan métodos de curación basados en sus necesidades terapéuticas, han surgido preguntas sobre los males que necesitan el cuidado de estos especialistas, así como sobre qué plantas se utilizan en sus procesos de bendición. Mediante la aplicación de dos cuestionarios diferentes (cuestionario 1 dirigido a los especialistas y cuestionario 2 destinado a la población), fue posible identificar ocho plantas utilizadas en este contexto, donde las concepciones de enfermedad y la garantía de cura legitiman esta práctica dentro de la población.

\section{PALABRAS-CLAVE}

Conocimiento local; Plantas de Poder; Etnomedicina; Etnobotánica. 


\section{INTRODUÇÃO}

A ideia de 'doença' mais difundida na sociedade advém de uma concepção da medicina dita "oficial" ou "erudita", a qual não é gerada dentro da cultura popular, sendo a sistematização da codificação científica de um tipo de saber produzido nas universidades, sustentada por um conhecimento que não existe difuso na cultura popular e codificada em livros com alcance desigual na sociedade; a mesma tem como objetivo a cura ou a supressão dos sintomas, preocupada mais com a doença e menos com a saúde, não sendo capaz nem de prever, nem de planificar a saúde da nossa população (OLIVEIRA, 1985, p. 46-47). Farias (2011, p. 85) aponta que "mesmo na atual sociedade ocidental em que a explicação da doença remete a causas anatomofisiológicas, devido à difusão do discurso médico, há também explicação de ordem social que remete às causas, mais especificamente ao sentido da doença para a sociedade".

Araújo (2002, p. 95) destaca que não se pode relacionar a doença apenas com patologias e disfunções orgânicas, mas também com as relações entre as pessoas e as relações entre estas e o mundo divino. Podemos complementar essa ideia com o apontamento de Farias (2011, p. 86), para o qual as diferentes explicações que as sociedades dão para a doença não são limitadas a sua causa, mas à busca de um sentido que explique a enfermidade do corpo e as circunstâncias desta em seu contexto social.

Em geral, as sociedades, principalmente as tradicionais, classificam as doenças mediante sua origem física, social e sobrenatural, sendo necessário diferentes tipos de tratamentos (DI STASI, 2007, p. 58). De acordo com o Decreto Federal nº 6.040 de 2007, povos e comunidades tradicionais são definições de grupos culturalmente diferenciados que se reconhecem como tais e que possuem formas próprias de organização social, ocupando e utilizando territórios e recursos naturais como condicionante para sua reprodução cultural, social, religiosa, ancestral e econômica, utilizando conhecimentos, inovações e práticas geradas e transmitidas pela tradição (MEDEIROS; ALBUQUERQUE, 2012, p. 23-24). Já Lucila Pinsard Vianna destaca que a expressão "população tradicional" é utilizada genericamente e atemporalmente para definir uma vaga categoria populacional (WIENCKE; LOBATO, 2017).

Dessa forma, para voltar ao seu estado de saúde, diversos grupos que compõem o meio social buscam formas terapêuticas que realmente lhes sejam eficazes no tratamento de seus males. Um desses meios é o sistema médico oficial, porém vale lembrar que o mesmo pode ser buscada antes, depois ou paralelamente a um meio tradicional ou popular de cura, ou seja, a partir de seu entendimento do mal que the acomete e da eficácia em seu tratamento a pessoa tem liberdade de escolher suas formas terapêuticas. Csordas (2008) coloca que:

"Uma compreensão da cura como um processo existencial requer a descrição dos processos de tratamento e especificação dos efeitos sociais e psicológicos concretos 
de práticas terapêuticas, bem como a determinação do que é considerado doença com necessidade de tratamento em contextos culturais específicos, é quando se pode dizer que a cura foi realizada" (p. 29).

Uma vez visto que a percepção de doença, e consequentemente da cura, como meio de se alcançar a saúde se aprofunda quando incluímos uma visão social, percebemos que a maneira de se estabelecer a sanidade advém do meio que melhor convém à/ao paciente, dando-lhe assim uma autonomia sobre si mesma/o como, também, proporciona um alto entendimento de si e do outro. Como mostra Rabelo (1994):

"A passagem da doença à saúde pode vir a corresponder a uma reorientação mais completa do comportamento do doente, na medida em que transforma a perspectiva pela qual este percebe seu mundo e relaciona-se com os outros" (RABELO, 1994, p. 47).

Foster e Anderson (1978) apud Martins (2003, p. 157), fazem a distinção de doença de acordo com o que classificam de regimes médicos, nesses regimes as doenças podem ser caracterizadas como sistemas personalístico e sistema naturalístico. No primeiro sistema, as doenças são causadas por ações de agentes malévolos e/ou punitivos. Já no segundo sistema, as bases da doença estão nas propriedades do corpo e de aspectos do cosmos que interferem no equilíbrio do mesmo.

A "doença" está compreendida na sociedade bem além da visão biomédica, pois antes de ser entendida como um mal causado por um agente microscópico, ela pode vir acompanhada de vários outros significados, causas e efeitos dentro dos contextos socioculturais em que é vivenciada por indivíduos. Portanto, as formas através das quais as pessoas buscam a cura estão fortemente associadas ao que se entende e se vivencia como doença.

Partindo da ideia de que o sistema de saúde oficial possui limitações em explicar as diversas formas de males presentes nos contextos tradicionais de práticas médicas, voltemos então nossas atenções a esses sistemas, como por exemplo: a medicina Chinesa; Ayurveda; Xamanismo; Herbalismo; Medicina tradicional; Medicina popular, etc. A medicina popular que, de acordo com Oliveira (1985) e Di Stasi (2007), pode ser compreendida como uma prática de cura próxima e acessível que oferece respostas concretas aos problemas de doença, possibilitando uma relação pessoal e humana de cura. Assim, este sistema médico aproxima e fortalece as relações sociais, pressupondo ajuda e solidariedade. É um tipo de conhecimento que se dissemina por toda a sociedade local/tradicional, passando de geração a geração e, na mesma geração, de pessoa para pessoa.

Na medicina popular podemos encontrar "agentes" que se destacam por terem um conhecimento que os tornam procuradas e reconhecidos entre o grupo, comunidade, região, etc. Essas pessoas são tidas como "especialistas", cada qual possuindo conhecimentos distintos sobre a cura, seja na utilização de animais, plantas, minerais, etc. Di Stasi (2007, 
p.61-62) pondera que mesmo havendo na sociedade o reconhecimento de especialistas como: benzedeiras, mateiros e outras/os grandes conhecedoras/es das plantas medicinais, a medicina popular não é típica ou específica de um único grupo étnico.

As práticas da medicina popular, mesmo estando presente nas vidas e sendo difundidas entre várias esferas de grupos sociais, acabam sendo deslegitimadas pelo sistema oficial de saúde, como no caso das benzedeiras e/ou curandeiros que utilizando-se de orações e plantas proporcionam a cura, uma vez que "o papel da planta é absorver o "espírito" da doença" (MOTA, 2007, p. 196). Sobre as orações, Amorim (2006) expõe que:

"Diante do doente o curandeiro tem uma oração para o mal de que está acometido o paciente. As rezas são beneficentes por excelência e são importantes porque só com elas, ao ver de certo curandeiro, se tratam determinadas doenças (as produzidas pelo ar, espinhela caída, olhado) para as quais não servem garrafadas ou outros remédios" (p. 17).

A partir do entendimento de que dentro de cada contexto social as pessoas buscam métodos de cura que satisfaçam suas necessidades terapêuticas, surgiram alguns questionamentos a respeito dos males que necessitam dos cuidados de rezadeiras/ores, bem como quais são as plantas utilizadas por essas/es especialistas em seus processos de cura. Assim, o presente trabalho realizou um levantamento etnobotânico sobre as plantas utilizadas por benzedeiras e curandeiros no contexto local de cura do povoado de Lages, município de Porto de Pedras - AL, buscando compreender possíveis relações entre a utilização dessas plantas e os males que levam as pessoas a procurarem esses agentes de cura.

\section{MATERIAL E MÉTODOS}

\section{ÁREA DE ESTUDO}

O município de Porto de Pedras localiza-se na microrregião do Litoral Norte do Estado de Alagoas, está a aproximadamente 100 km da capital Maceió. Sua área é de 257,396 km². Possui clima tropical litorâneo úmido e vegetação típica de Mata Atlântica. Dados do Instituto Brasileiro de Geografia Estatística (IBGE, 2018), mostram que a população de Porto de Pedras, de acordo com o censo de 2010, era de 8.429 habitantes, sendo que a estimativa para o ano de 2018 foi em torno de 7.873 pessoas.

A assistência em saúde da população é realizada através de quatro unidades básicas de saúde que fazem parte do Sistema único de Saúde (SUS), localizadas nos povoados de Tatuamunha, de Lages, do Curtume e na Fazenda Canavieiras. Segundo documento fornecido pela Secretaria de Saúde do município, aproximadamente 350 pessoas são atendidas por mês em diferentes especialidades. A falta e/ou a precarização no atendimento dessas unidades de saúde, que muitas vezes não satisfazem as pessoas que a procuram, pode 
ser um fator que indique a importância das benzedeiras e dos curandeiros nos processos de cura dessa população.

\section{COMUNIDADE ESTUDADA}

A Lages, como é mais conhecido o povoado, localiza-se a aproximadamente cinco quilômetros do centro administrativo do município. Sua população concentra-se às margens da estrada AL-101- Norte, entre o manguezal e o Oceano Atlântico (Figura 1). Dados do Departamento de Informática do Sistema único de Saúde do Brasil (DATASUS, 2015) apontam que no referido ano a população de Lages era de 1.597 habitantes, distribuídos em 441 famílias cadastradas na unidade básica de saúde do mesmo. Essas famílias muitas vezes não conseguem atendimento, pois a falta de médicas/os é um problema recorrente no povoado, o que leva ao deslocamento para algum povoado vizinho ou ao centro administrativo do município a fim de serem atendidas/os pelo Programa de Saúde à Família PSF.

Figura 1. Lugares-tenentes: Vista aérea mostrando a localização do povoado de Lages às margens da AL-101- Norte, entre o manguezal e o oceano atlântico.

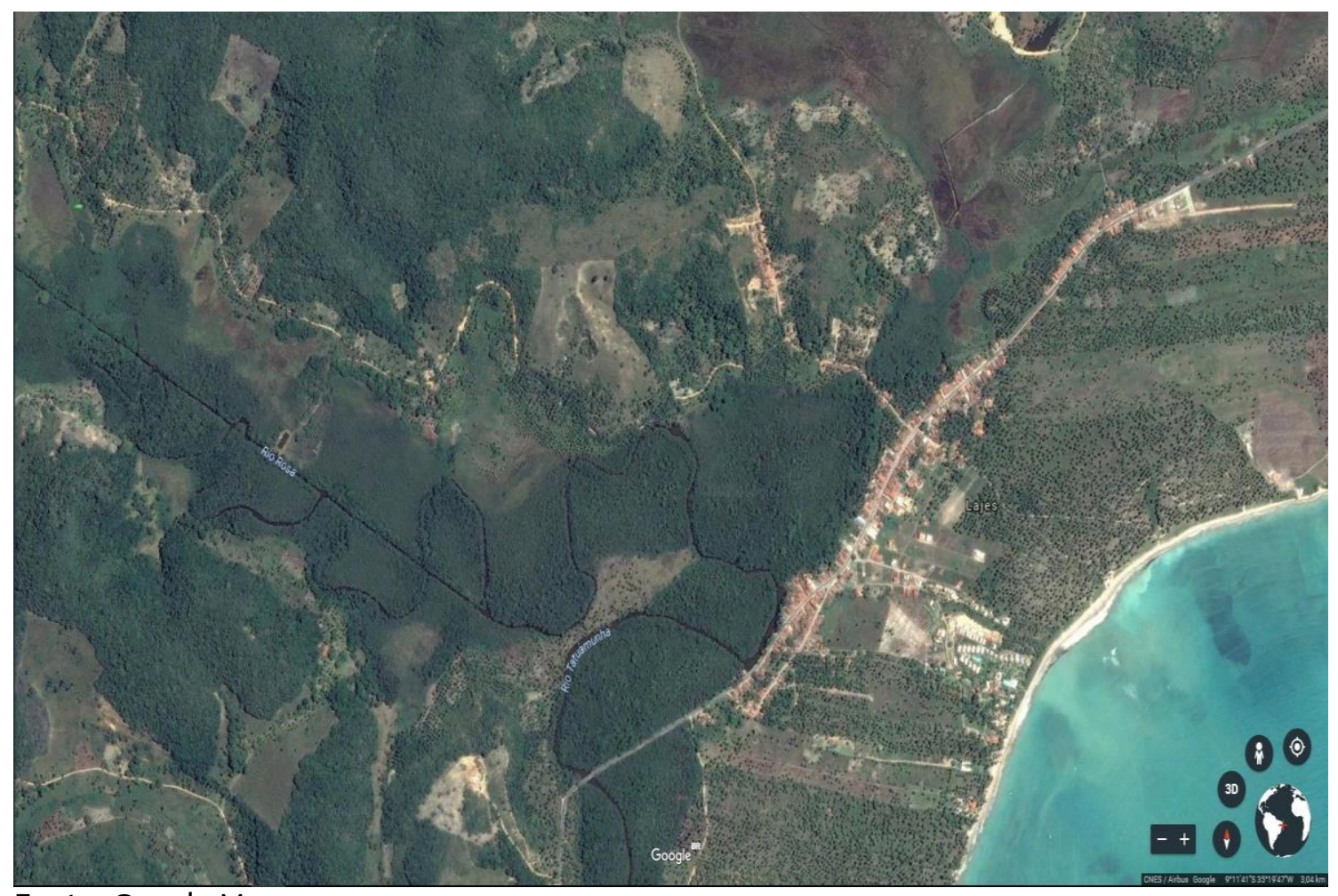

Fonte: Google Maps. 


\section{COLETA DE DADOS}

Foram conduzidos dois diferentes roteiros, em forma de questionários semiestruturados, visando orientar a pesquisa de campo. O questionário 1 foi direcionado às benzedeiras e curandeiros e o questionário 2 foi destinado à população local. Foram levantadas tanto informações socioculturais, considerando aspectos como idade, gênero, escolaridade, tempo de residência, ocupação e religião. Também foram levantadas informações sobre a procura de benzedeiras e curandeiros e com relação às plantas utilizadas na cura por essas/es especialistas. Para viabilizar a confirmação de informações decorrentes das aplicações do questionário 1, quando permitido pelas/os voluntárias/os, foram feitas gravações em áudio das entrevistas.

Na abordagem às interlocutoras, foi utilizada a metodologia da observação participante, onde a presença do observador numa situação social é mantida para fins de investigações científicas. Assim, o observador fica face a face com os observados e participando com eles em seu ambiente natural de vida coleta os dados. O observador é parte do contexto observado, ao mesmo tempo que modifica é modificado por esse contexto (CICOUREL, 1969 apud HAGUETTE, 2007, p. 71).

Para facilitar a aplicação dos questionários, o povoado foi dividido em cinco áreas (Figura 2): a $1^{\text {a }}$ área, em amarelo, representa a Rua 09 de Junho e a rua da praia; a $2^{a}$ área, em laranja claro, é composta pela Praça Nicolau Paes Sarmento (em vermelho) e o sítio Lages; a $3^{a}$ área é composta pela Rua Bernardino Araújo Cunha, em azul escuro, mais conhecida como "rua de baixo", e pela Rua Prof. a Filomena Verçosa Reis, em azul claro, "rua de dentro" como é chamada no local. A 4 a área, em verde, compreende a rua da ponte e a Rua do Goití e a $5^{\text {a }}$ área, em laranja escuro, compreende a Rua João Vicente Damasceno, ou rua da "barguilha". A estrela e a cruz representam, respectivamente, a unidade de básica de saúde e a capela.

Figura 2. Lugares-tenentes: Croqui do povoado de Lages, Porto de Pedras - AL, mostrando a divisão das áreas de realização da pesquisa.

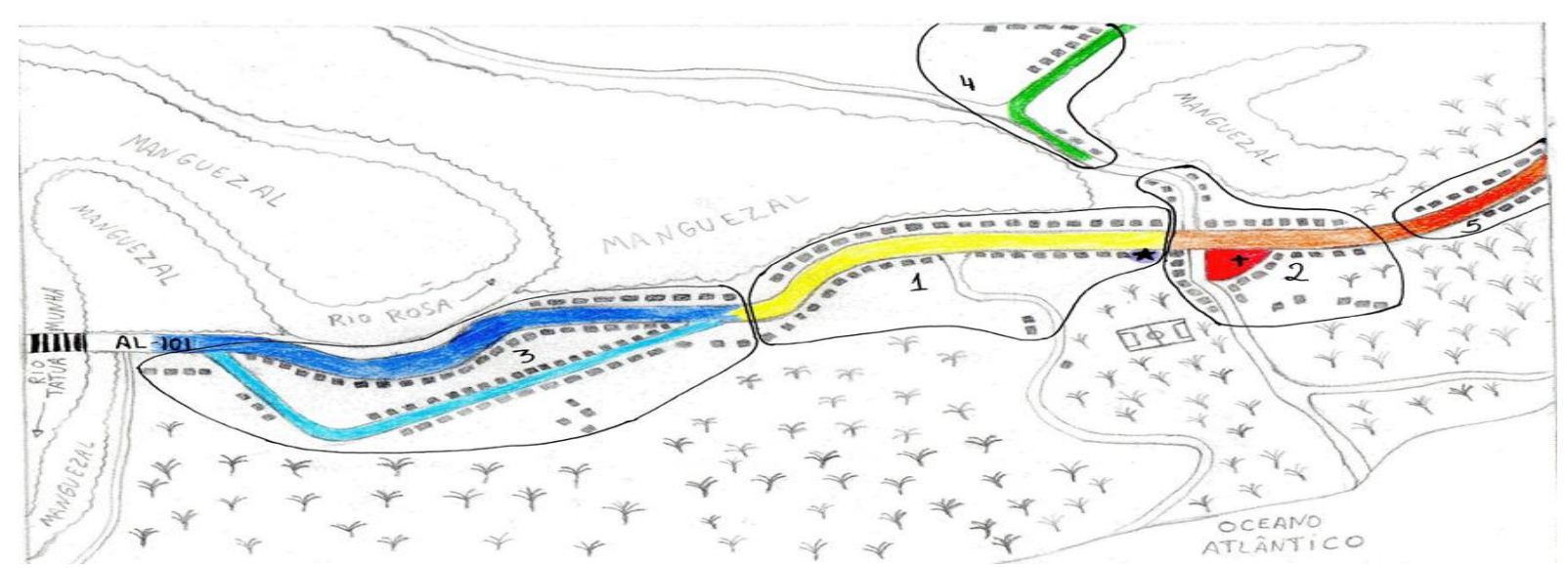


No caso do questionário 1, as visitas foram diretas, uma vez que as/os benzedeiras e curandeiros foram indicados pela população. Houve indicações de uma benzedeira e um curandeiro na $3^{a}$ área, mas apenas a benzedeira aceitou participar da pesquisa e na $4^{a}$ área houve um curandeiro. Para cada área foram destinados 20 questionários do tipo 2, sendo que para cada lado da rua foram destinados dez roteiros. As visitas se deram na proporção de uma para uma, ou seja, para cada casa visitada a próxima foi pulada, seguindo-se adiante.

As entrevistas foram realizadas através do contato estabelecido com as/os interlocutoras/es, de forma voluntária, com a leitura do Termo de Consentimento Livre e Esclarecido - TCLE1 e só após a assinatura do mesmo deu-se início as perguntas. Quando necessário fez-se uso de uma almofada de carimbo para impressão digital, garantindo assim a legitimidade de seu consentimento.

Mesmo havendo um questionário como guia, as perguntas foram feitas de forma dialógica e livre, deixando as/os interlocutoras/es a vontade para respondê-las. As entrevistas ocorreram nos dias 10 e 11 de setembro e 26, 27 e 28 de dezembro de 2016. Uma vez com os materiais de pesquisa em mãos (questionários, prancha, caneta, câmera e gravador), foram feitas visitas às casas, quando não se encontravam moradoras/es seguia-se para a próxima.

\section{RESULTADOS}

\section{DOS QUESTIONÁRIOS APLICADOS}

No total, foram aplicados 102 questionários, dos quais dois foram destinados à benzedeira/curandeiros (questionário 1) e 100 destinados à população (questionário 2).

\section{BENZEDEIRA E CURANDEIRO}

A.B.S. Senhora de 81 anos, aposentada tanto na carteira de trabalho quanto no ofício de benzedeira, atualmente mora com sua filha, genro e netos, porém morava só, tendo como companhia seus familiares que moravam por perto e as pessoas que procuravam seus serviços em sua casa na rua de dentro. Não chegou a estudar, pois foi criada longe da "rua" 2, não tendo acesso à escola.

De religião católica, foi benzedeira durante muitos anos de sua vida. Atualmente por motivos de saúde decorrentes da idade está impossibilitada de benzer e, mesmo

\footnotetext{
1 A pesquisa ocorreu após o parecer positivo do Comitê de Ética em Pesquisa da Universidade Federal de Alagoas (CEP - UFAL) com n ${ }^{\circ}$ CAEE: 55395016.8.0000.5013.

${ }^{2}$ Nome genérico dado a cidades, povoados, etc. que se encontram próximos ou distantes de sítios e/ou fazendas da região.
} 
encontrando-se acamada, disponibilizou-se de bom grado a contar um pouco de sua história e partilhar seus conhecimentos. Sua família faz uso de plantas e também se curava com ela. Aos 12 anos aprendeu a curar com a irmã de sua patroa, da qual ela lembra que:

Na casa grande ela forrava a esteira no chão, colocava os filhos dos trabalhadores e curava. A.B.S. 81 anos.

Realizou sua primeira cura aos 14 anos, tendo sua mãe como paciente. Infelizmente não passou adiante o conhecimento da cura. Citou um total de três plantas que utiliza para benzer (Tabela 1).

A.M.A.S. Rapaz de 21 anos que estudou até o ensino fundamental, pois precisou interromper seus estudos e não chegou a concluir essa etapa de seu processo escolar. Mora com mais quatro familiares. Filho de santo da umbanda e curador, aprendeu aos 16 anos com seu pai de santo, sendo que se iniciou na cura aos 19 anos.

Sua família faz o uso de plantas e também o procuram para serem curadas em sua casa na rua do Goiti (4⿳a área, fig. 2). Até então não ensinou a curar. Citou um total de seis plantas que utiliza em sua benzeção (Tabela 1).

Tabela 1. Lugares-tenentes: Plantas utilizadas pela benzedeira e pelo curandeiro em suas consultas. Legenda: $X$ = responsável pela citação da planta.

\begin{tabular}{|c|c|c|c|c|c|}
\hline Nome local & Espécie & Família & Benzedeira & Curandeiro & Indicações \\
\hline Aroeira & $\begin{array}{l}\text { Schinus } \\
\text { terebinthifolia } \\
\text { Raddi }\end{array}$ & Anacardiaceae & & $\mathrm{x}$ & desfazer feitiço \\
\hline Pinhão roxo & $\begin{array}{l}\text { Jatropha } \\
\text { gossypiifolia L. }\end{array}$ & Euphorbiaceae & $\mathrm{x}$ & $\mathrm{x}$ & $\begin{array}{l}\text { mau olhado/ } \\
\text { desfazer feitiço }\end{array}$ \\
\hline Carrapateira & $\begin{array}{l}\text { Ricinus } \\
\text { communis L. }\end{array}$ & Euphorbiaceae & & $\mathrm{x}$ & mau olhado \\
\hline Manjerioba & $\begin{array}{l}\text { Senna } \\
\text { occidentalis (L.) } \\
\text { Link }\end{array}$ & Fabaceae & $\mathrm{x}$ & & $\begin{array}{l}\text { mau olhado e } \\
\text { ventre caído }\end{array}$ \\
\hline Manjericão & $\begin{array}{l}\text { Ocimum } \\
\text { basilicum L. }\end{array}$ & Lamiaceae & & $\mathrm{x}$ & mau olhado \\
\hline Jurema & $\begin{array}{l}\text { Vitex agnus- } \\
\text { castus L. }\end{array}$ & Lamiaceae & & $\mathrm{x}$ & desfazer feitiço \\
\hline Vassourinha & Scoparia dulcis L. & Plantaginaceae & $\mathrm{x}$ & $\mathrm{x}$ & mau olhado \\
\hline
\end{tabular}

Legenda: $\mathrm{X}=$ responsável pela citação da planta.

Farias (2011) e outras/os pesquisadoras/es apontadas/os por Araújo (apud Loyola, 1984) distinguem de forma hierárquica as/os curandeiras/os de rezadeiras/es ou 
benzedeiras/ores, no entanto essa hierarquia não ocorre no povoado de Lages, uma vez que nessa população curandeiras/os, rezadeiras/rezadores e benzedeiras/ores são termos comuns que categorizam as/os mesmas/os especialistas, sendo assim, tidos como sinônimos.

\section{POPULAÇÃO}

Das 100 pessoas entrevistadas a maioria é de mulheres (gráfico a), possuindo entre 21 e mais de 70 anos de idade. A escolaridade dessa população varia entre pessoas iletradas (pessoas que não frequentaram a escola formal) até as que possuem o ensino superior (gráfico b) e que moram no povoado em um período entre cinco e mais de 65 anos (gráfico c).

Gráfico 1. Lugares-tenentes: Relação entre o quantitativo de mulheres e homens participantes da pesquisa.

\section{População Entrevistada}

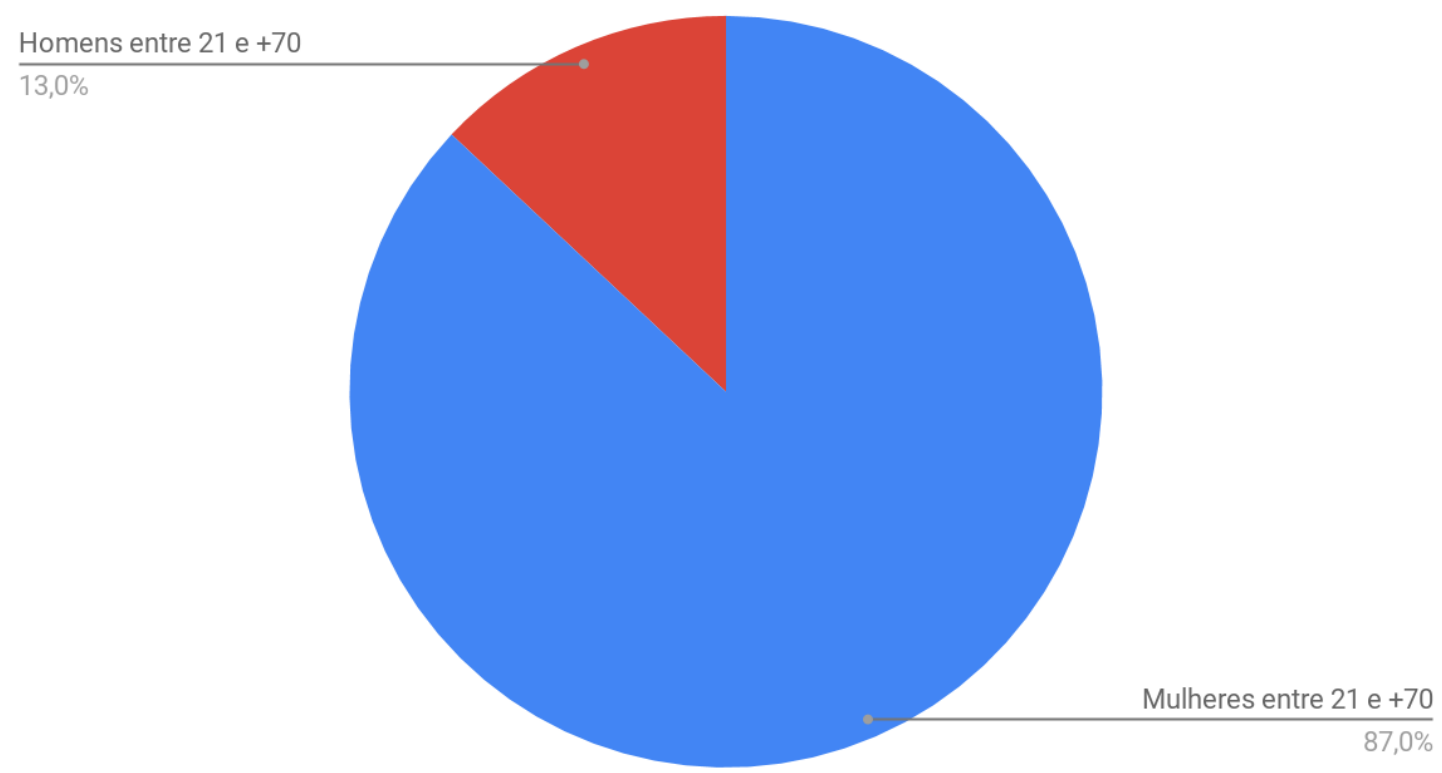


Gráfico b: Escolaridade das/os interlocutoras/es.

\section{Escolaridade}

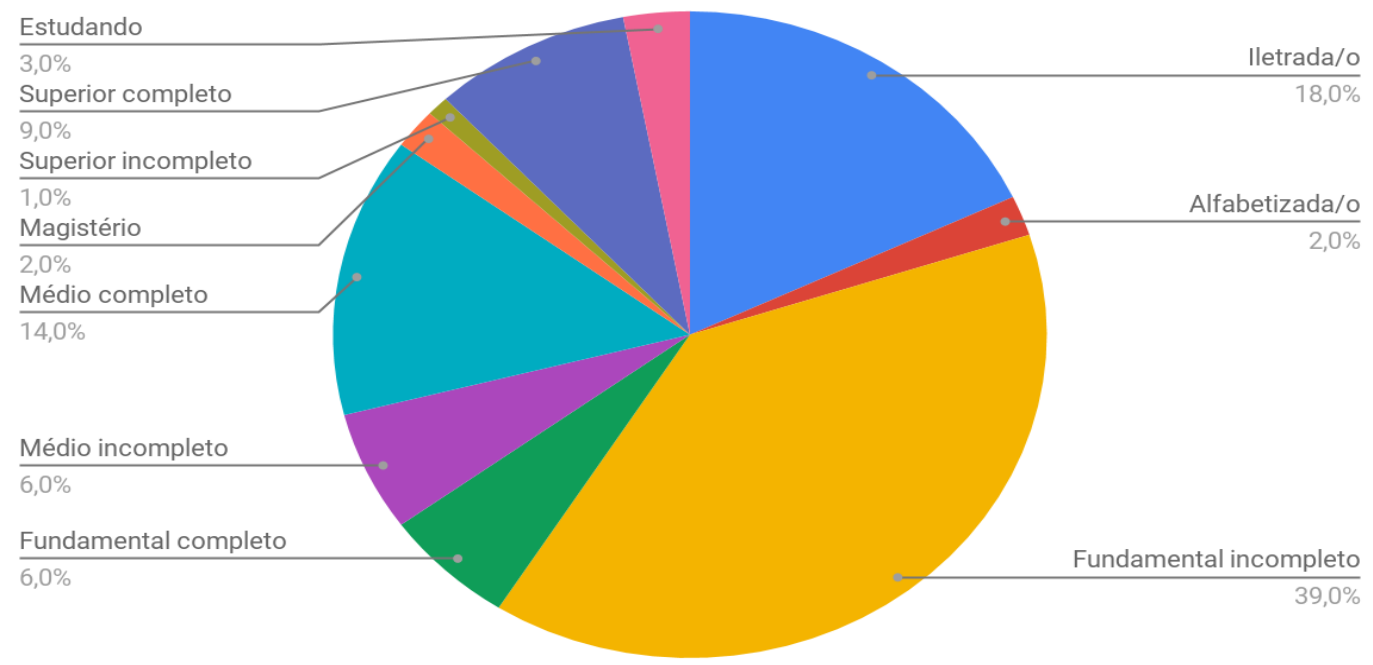

Gráfico c: Tempo de residências das/os interlocutoras/es no povoado.

\section{Tempo de residência no povoado de Lages}

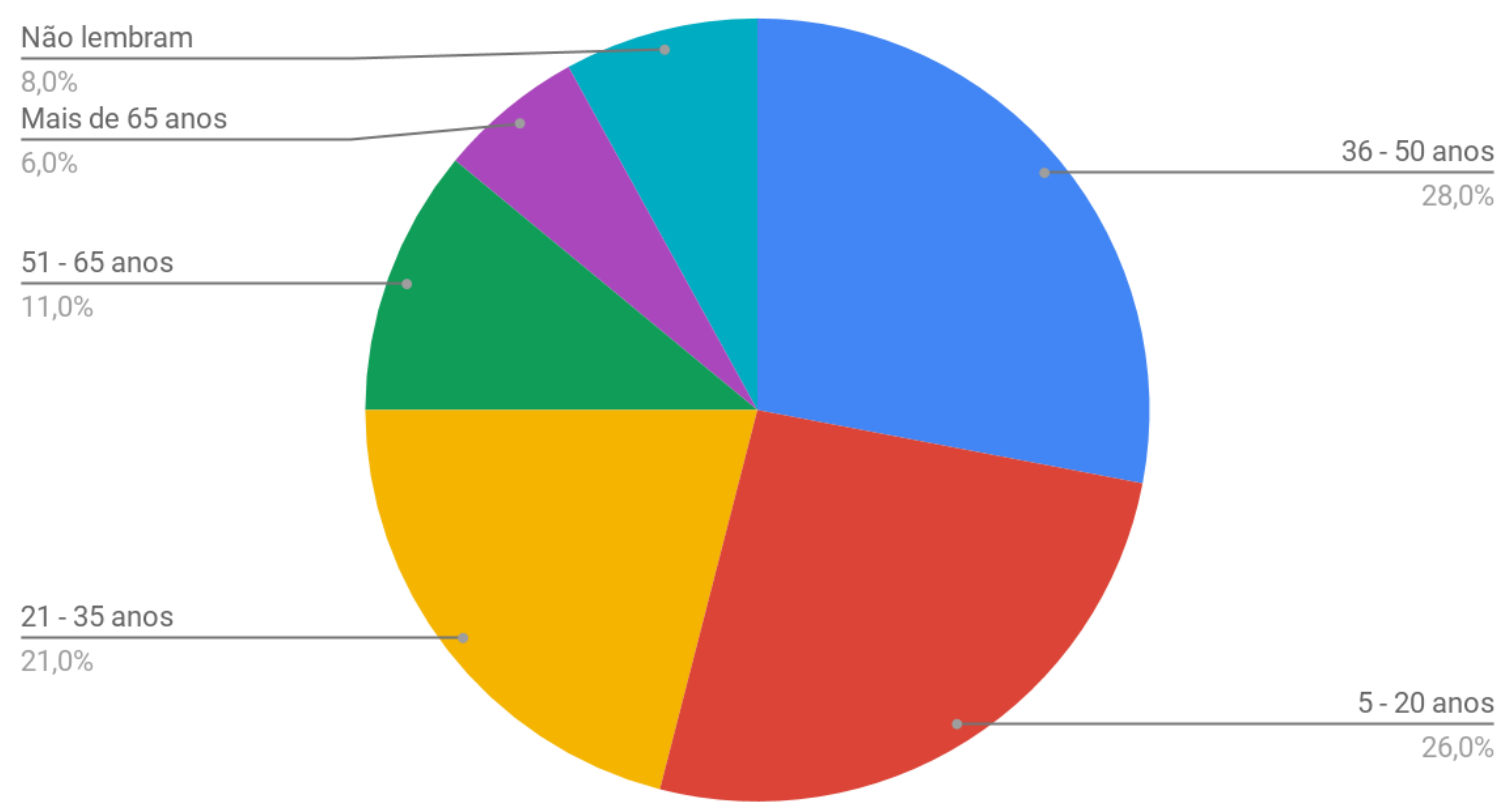

Buscando compreender se há alguma ligação possível entre a religião e a procura por benzedeiras e curandeiros por essas pessoas, uma vez que tabus religiosos podem interferir na busca por essas/es especialistas, perguntou-se sobre qual/quais religião/ões pertencem: $66 \%$ se consideram católicas/os; $20 \%$ se afirmaram evangélicas/os, $1 \%$ batista e $1 \%$ adventista. Uma pessoa (1\%), tem o catolicismo e o espiritismo como religiões, não foi 
possivel esclarecer se é da doutrina kardecista ou de religiões de matrizes africana. Ainda houveram 11 pessoas (11\%) que afirmaram não possuir religião, porém acreditam em Deus.

Uma vez perguntadas/os se conheciam as plantas utilizadas na benzeção, 40\% indicaram conhecer as mesmas. Dessas pessoas, 35 confirmaram que procuram esses serviços de cura e cinco alegaram que "não", porém duas ressaltaram que já as/os procuraram em outro momento da vida. Os motivos alegados para essa mudança foram a conversão para a religião evangélica e a diminuição desses especialistas de cura no povoado. No total foram citadas sete plantas (Tabela 2) reconhecidas pela população como sendo utilizadas pelas benzedeiras e curandeiros do povoado. Estas costumam ser empregadas para sanar males como mau-olhado; espinhela caída; ventre caído; dor de dente e doenças de criança.

Tabela 2. Lugares-tenentes: Plantas reconhecidas pela população como as utilizadas nos processos de benzeção.

\begin{tabular}{|l|l|l|l|l|}
\hline Nome local & Espécie & Família & $\mathrm{N}^{\circ}$ de Citações & Indicações \\
\hline Pinhão roxo & $\begin{array}{l}\text { Jatropha } \\
\text { gossypiifolia } \text { L. }\end{array}$ & Euphorbiaceae & 36 & mau olhado \\
\hline Carrapateira & $\begin{array}{l}\text { Ricinus communis } \\
\text { L. }\end{array}$ & Euphorbiaceae & 01 & $\begin{array}{l}\text { saltador (caroços em } \\
\text { crianças) }\end{array}$ \\
\hline Manjerioba & $\begin{array}{l}\text { Senna occidentalis } \\
\text { (L.) Link }\end{array}$ & Fabaceae & 14 & $\begin{array}{l}\text { mau olhado e ventre } \\
\text { caído }\end{array}$ \\
\hline Manjericão & $\begin{array}{l}\text { Ocimum basilicum } \\
\text { L. }\end{array}$ & Lamiaceae & 02 & mau olhado \\
\hline Jurema & $\begin{array}{l}\text { Vitex agnus-castus } \\
\text { L. }\end{array}$ & Lamiaceae & 01 & mau olhado \\
\hline Vassourinha & Scoparia dulcis L. & Plantaginaceae & 31 & mau olhado \\
\hline Chanana & $\begin{array}{l}\text { Turnera subulata } \\
\text { Sm. }\end{array}$ & Turneraceae & 01 & \\
\hline
\end{tabular}

\section{DISCUSSÕES E CONCLUSÕES}

Referente às plantas citadas pela benzedeira e pelo curandeiro, quatro foram apontadas exclusivamente pelo curandeiro: aroeira (Schinus terebinthifolia Raddi); carrapateira (Ricinus communis L.); manjericão (Ocimum basilicum L.) e jurema (Vitex agnuscastus L.). Duas plantas foram citadas por ambos: pinhão-roxo (Jatropha gossypiifolia L.) e vassourinha (Scoparia dulcis L.) e uma foi citada exclusivamente pela benzedeira: manjerioba (Senna occidentalis (L.) Link), sendo atribuídos o poder de retirar mau olhado, desfazer feitiços e curar ventre caído. Ao analisar um estudo realizado em Pernambuco por Silva e Andrade (2005), foi possível constar as espécies: Jatropha gossypiifolia L.; Ricinus communis L. e Scoparia dulcis L. na categoria de plantas "mágicas" indicadas para banhos, defumadores, benzeduras e rezas. No mesmo trabalho foi atribuído à espécie Vitex agnuscastus L. a categoria medicinal, porém não constam quais são suas indicações. 
Em um levantamento realizado na Paraíba por Oliveira eTrovão (2009) sobre plantas utilizadas em rituais de rezas e benzeduras elas relatam a utilização de Jatropha gossypiifolia L. para o tratamento de quebranto e dor no ventre, sendo que essa planta foi apontada como a mais relevante. As autoras ainda indicaram as espécies: Ocimum basilicum L., no tratamento do quebranto, dor de cabeça e de dente; Ricinus communis L., para "coisas pesadas"; e Senna occidentalis (L.), para tratar de espinhela caída e dor de cabeça.

Em sua dissertação sobre as rezadeiras de Cruzeta - RN, Santos (2007) organizou as definições das doenças e os sintomas de alguns males tratados por elas:

"Olhado ou mau-olhado é uma doença que vai debilitando o indivíduo, aos poucos, até a morte, se a pessoas não procurarem alguém que reze. É proveniente de um fascínio (admiração) sobre quaisquer aspectos, tanto em seres humanos, quanto em animais e plantas" (SANTOS, 2007, p. 79).

"Existe uma semelhança quanto ao tratamento e os sintomas entre o olhado e o quebrante. No entanto, algumas rezadeiras estabelecem diferenças entre estas duas doenças. O olhado é botado pelo indivíduo que apenas olha, sem falar nada; enquanto para botar o quebrante, a pessoa olha e se admira de qualquer aspecto ligado à vítima" (SANTOS, 2007, p. 81).

"Vento caído ou ventre caído doença específica de criança, e que está relacionada a desarranjo intestinal e a desidratação. Os sintomas são fezes verde, é provocado por sustos" (SANTOS, 2007, p. 82).

Em um estudo sobre plantas medicinais e ritualísticas comercializadas no Rio de Janeiro, entre as especies listadas por Maioli-Azevedo \& Fonseca-Kruel (2007) constam: Schinus terebinthifolia Raddi; Jatropha gossypiifolia L. e Ocimum basilicum L., indicadas para banho ritualístico. Levantamentos etnomédicos realizados por Almeida (2003 apud MAIOLI-AZEVEDO; FONSECA-KRUEL, 2007) nas regiões metropolitanas do Rio de Janeiro e Salvador registraram intenso consumo de espécies vegetais de origem africana por terreiros afro-brasileiros.

Sugiro uma possível comparação da indicação da espécie Ricinus communis L. (origem africana) feita por Oliveira \& Trovão (2009), ao qual atribuiu-se o poder para aliviar as "coisas pesadas" (feitiços, mau-olhado, etc.), com as espécies Jatropha gossypiifolia L., planta nativa com distribuição nas cinco regiões do Brasil (REFLORA, 2018), e Schinus terebinthifolia Raddi, que ocorre ao longo da Mata Atlântica desde o Rio Grande do Norte até o Rio Grande do Sul (LORENZI, 2008, p. 63). Estas últimas foram citadas pelo curandeiro entrevistado para "desfazer feitiço". Assim, uma vez que o curandeiro pertence a uma religião de matriz africana, podemos considerar estes aspectos um indício de um possível processo de adaptação biocultural na utilização da flora local em suas formas terapêuticas. Almeida (2000), coloca que:

"Os levantamentos etnomédicos realizados, demonstram a forte influência da herança cultural africana na medicina popular do Brasil, principalmente no norte, nordeste e sudeste do país. Com a vinda dos africanos para o Brasil, após três séculos de tráfico escravo, muitas foram as espécies vegetais trazidas, substituídas por outras de morfologia externa semelhante, enquanto algumas foram levadas daqui para o continente africano" (p.34). 
Ao mencionarem como se iniciaram na cura e se possuem aprendizes, A.B.S relatou que com 12 anos aprendeu a curar com a irmã de sua patroa, e aos 81 anos não havia ensinado o que aprendeu. Já A.M.A.S contou que aprendeu aos 16 anos com seu pai de santo e informou que a iniciação ocorre dentro dos preceitos de sua religião. Seguindo a afirmação de Kleinman (1980 apud FARIAS, 2011, p. 38), são diversas as formas de aquisição dos conhecimentos pelas/os especialistas, podendo, inclusive a cura ser um dom natural. Desse modo, quando esses especialistas ensinam a benzer não o fazem para qualquer pessoa e a qualquer momento. Às vezes, por diferentes motivos, nunca chegam a ensinar. Quando repassam seus conhecimentos, geralmente o fazem para pessoas sensíveis e que já manifestaram esse dom, ou simplesmente deixam que estas pessoas observem as sutilezas do saber sentir e saber fazer (MAZUREMA, 2016, p. 39).

As diferenças na realização da cura podem ser facilmente compreendidas quando entendemos que a prática do benzimento pode ser realizada tanto por mulheres quanto por homens, de diversas origens, grupos e identidades sociais. Uma benzedeira pode ser uma pescadora artesanal, uma cigana, uma pecuarista familiar, ser uma quilombola ou mãe de santo. Porém, para a comunidade a qual pertence, será sempre reconhecida como benzedeira (MAZUREMA, 2016, p. 33 e 36). Além disso, cada ritual é uma agregação de símbolos e atua como um dinamismo e potencial criativo dos agentes (TUNER, 1968 apud HELMAN, 2003, p. 206). Mesmo havendo muitas semelhanças nas formas de benzer, há também muitas particularidades (MAZUREMA, 2016, p. 40).

Ao compararmos as plantas utilizadas pela benzedeira e pelo curandeiro entrevistados com as indicadas pela população (Tabela 3), notamos tanto similaridades, quanto divergências entre plantas e suas indicações. Isto pode ser explicado pelo fato que, dentro do contexto onde ocorre esse processo de cura, há o fortalecimento das relações sociais, já que a prática da cura pressupõe ajuda e solidariedade. Além disso, o benzimento pode ser considerado uma medicina próxima e acessível (OLIVEIRA, 1985, p. 8-9). Isto leva a uma relação de confiança entre especialistas e pacientes, gerando assim uma transmissão desse conhecimento. Deste modo, as/os aprendizes não precisam necessariamente estar doentes ou procurando conhecer as utilizações das plantas. 
Tabela 3. Lugares-tenentes: comparativo entre as plantas utilizadas pela benzedeira e pelo curandeiro e as apontadas pela população nesse processo de cura.

\begin{tabular}{|c|c|c|c|c|c|}
\hline N.L & Espécie & C.E & C.P & I.E & I.P \\
\hline Pinhão roxo & $\begin{array}{l}\text { Jatropha } \\
\text { gossypiifolia L. }\end{array}$ & $\mathrm{B} / \mathrm{C}$ & 36 & $\begin{array}{l}\text { mau olhado/ } \\
\text { desfazer feitiço }\end{array}$ & mau olhado \\
\hline Manjericão & $\begin{array}{l}\text { Ocimum } \\
\text { basilicum L. }\end{array}$ & $\mathrm{C}$ & 2 & mau olhado & mau olhado \\
\hline Carrapateira & $\begin{array}{l}\text { Ricinus } \\
\text { communis L. }\end{array}$ & $\mathrm{C}$ & 1 & mau olhado & $\begin{array}{l}\text { saltador (caroços } \\
\text { em crianças) }\end{array}$ \\
\hline Aroeira & $\begin{array}{l}\text { Schinus } \\
\text { terebinthifolia } \\
\text { Raddi } \\
\end{array}$ & $\mathrm{C}$ & ------ & desfazer feitiço & ----- \\
\hline Vassourinha & $\begin{array}{l}\text { Scoparia dulcis } \\
\text { L. }\end{array}$ & $\mathrm{B} / \mathrm{C}$ & 31 & mau olhado & mau olhado \\
\hline Manjerioba & $\begin{array}{l}\text { Senna } \\
\text { occidentalis (L.) } \\
\text { Link }\end{array}$ & B & 14 & $\begin{array}{l}\text { mau olhado e } \\
\text { ventre caído }\end{array}$ & $\begin{array}{l}\text { mau olhado e } \\
\text { ventre caído }\end{array}$ \\
\hline Chanana & $\begin{array}{l}\text { Turnera } \\
\text { subulata } \mathrm{Sm} .\end{array}$ & ------ & 1 & ------- & mau olhado \\
\hline Jurema & $\begin{array}{l}\text { Vitex agnus- } \\
\text { castus L. }\end{array}$ & $\mathrm{C}$ & 1 & desfazer feitiço & mau olhado \\
\hline
\end{tabular}

Legendas: $\mathrm{N} . \mathrm{L}=$ = nome local; $\mathrm{C} . \mathrm{E}=$ citações especialista; $\mathrm{C} . \mathrm{P}=$ citações população; I.E = indicações especialistas; I.P = indicações população; $B$ = benzedeira; $C=$ curandeiro e $B / C=$ Benzedeira e curandeiro.

As experiências de vida dessas pessoas, principalmente no contexto referente à dinâmica saúde/doença, legitimam e afirmam a importância dessa prática dentro da população. Nesse contexto, a prática do benzimento possibilita para essa população a garantia de cura dos males que a medicina oficial não pode thes proporcionar. Além disso, as próprias concepções locais de saúde e doença e a convivência em comunidade refletem na dinâmica pela qual o conhecimento a respeito das plantas utilizadas por essas/es especialistas é gerado, bem como na transmissão desse conhecimento.

\section{REFERÊNCIAS}

ALMEIDA, M.Z. Plantas medicinais e ritualísticas / Mara Zélia de Almeida. Salvador: EDUFABA, 2000.

AMORIM, J.P. Medicina Popular em Alagoas. 2ª ed. Maceió Editora Graciliano Ramos, 2006.

ARAÚJO, M.A. M. Das ervas medicinais à fitoterapia. Ateliê Editorial. 2002.

CSORDAS, Thomas. Corpo/significado/cura. Porto Alegre: Editora da UFRGS, v. 5, 2008.

DI STASI, L.C. Plantas medicinais: verdades e mentiras: o que os usuários e os profissionais de saúde precisam saber. São Paulo: UNESP, 2007.

FARIAS, I.S. Doenças, dramas e narrativas entre os índios Jeripankó no sertão de Alagoas / Ivan Soares Farias. -Maceió: EDUFAL, 2011. 
HAGUETTE, T.M.F. Metodologias qualitativas na sociologia. 11. Ed, Petrópolis, RJ: Vozes, 2007.

HELMAN, C.G. Cultura, saúde e doença / Cecil G. Helman; trad. Claudia Buchweitz e Pedro M. Garcez. 4.a ed. Porto Alegre: Artmed, 2003.

IBGE, 2018. Disponível em: <https://cidades.ibge.gov.br/brasil/al/porto-de-pedras/panorama> . Acesso em Janeiro/2018.

LORENZI, H.; MATOS, F.J.A. Plantas medicinais no brasil: nativas e exóticas. 2. Ed, Nova Odessa, SP: Instituto Plantarum, 2008.

LOYOLA, M.A. Médicos e curandeiros conflito social e saúde. DIFEL Difusão Editorial S.A. São Paulo SP, 1984.

MAIOLLI-AZEVEDO, V.; FONSECA-KRUEL, V.S. Plantas medicinais e ritualísticas vendidas em feiras livres no Município do Rio de Janeiro, RJ, Brasil: estudo de caso nas zonas Norte e Sul. Acta Botanica Brasilica, v. 21, n. 2, p. 263-275, 2007.

MARTINS, S.A.C. Gender and Reproduction: EmbodIment among the Karírí- Shocó of Northeast Brazil. Tese de Doutorado. Universidade de Manitoba, Canada, 2003.

MAZUREMA, J. Povos e Comunidades Tradicionais do Pampa. Porto Alegre: Fundação Luterana de Diaconia, 2016.

MEDEIROS, Maria F. Trindade; ALBUQUERQUE, Ulysses Paulino de. Dicionário brasileiro de etnobiologia e etnoecologia. Editora Nupeea, Recife - PE, 2012.

MOTA, Clarice Novaes da. Os filhos da Jurema na floresta dos espíritos: ritual e cura entre dois grupos indígenas do nordeste brasileiro. Maceió: EDUFAL, 2007.

OLIVEIRA, E.C.S.; TROVÃO, D.M.B.M. 0 uso de plantas em rituais de rezas e benzeduras: um olhar sobre esta prática no estado da Paraíba. Revista Brasileira de Biociências, Porto Alegre, v.7, n. 3, p. 245-251, 2009.

OLIVEIRA, E.R. 0 que é medicina popular. São Paulo: Abril Cultural: Brasiliense, 1985.

RABELO, M.C.M. "Religião, Ritual e Cura”. In: ALVES, P.C.; MINAYO, M.C.S. (org.). Saúde e doença: um olhar antropológico. Rio de Janeiro: FIOCRUZ, 1994. p. 47-56.

REFLORA.

Disponível

em: <http://reflora.jbrj.gov.br/reflora/listaBrasil/ConsultaPublicaUC/ConsultaPublicaUC.do\#CondicaoTaxo nCP >. Acesso em janeiro/2018.

SANTOS, Francimário Vito dos. 0 ofício das rezadeiras: um estudo antropológico sobre as práticas terapêuticas e a comunhão de crenças entre as rezadeiras de Cruzeta/RN. Dissertação de Mestrado em Antropologia Social - UFRN, 2007. 
SILVA, A.J.R.; ANDRADE, L.H.C. Etnobotânica nordestina: estudo comparativo da relação entre comunidade e vegetação na zona do Litoral - Mata do Estado de Pernambuco, Brasil. Acta Botanica Brasilica, v. 19, n. 1, p. 45-60, 2005.

SECRETARIA DE ASSISTÊNCIA À SAÚDE / DAB - DATASUS. Secretaria Municipal de Saúde. SIAB - Sistema de Informação de Atenção Básica. Consolidado das Famílias Cadastradas do ano de 2015.

WIENCKE, F.; LOBATO, A.O.C. Serviços ambientais promovidos pelos povos e comunidades tradicionais: um enfoque sobre o patrimônio cultural imaterial. Campo Jurídico, v. 5, n.1, p. 127-160, 2017.

Recebido em 17 de junho de 2019. Aprovado em 16 de setembro de 2019. 